\title{
Analysis on the Protection and Tourism Exploitation of Yunnan-Vietnam Railway
}

\author{
Lijun Shi \\ Yunnan University of Business Management \\ Kunming, China 650106
}

\author{
Hong Pan \\ Yunnan Arts University \\ Kunming, China 650500
}

\begin{abstract}
The Yunnan Vietnam Railway is one of the important materials for studying the history of Chinese railways. There are many valuable cultural relics on the Vietnam Vietnam Railway Corridor. After historical accumulation, the historical and cultural value is constantly accumulating, forming the unique cultural connotation of Yunnan. Based on the resource status and the present tourism situation of Yunnan Vietnam Railway economic belt, this paper puts forward the development idea of "Yunnan Vietnam Railway Cultural Tourism Corridor". The key to build three tourism growth area, namely Yiliang-Shilin-Mile area, MengziJianshui area and Hekou area; Taking the Yunnan Vietnam Railway as the development line, Taking the Kunming - Mile Mengzi - Hekou expressway as the auxiliary line, Highlighting the three characteristics of the publicity points which are Railway - Highway leisure cultural tourism, railway - Highway characteristic catering tourism, national and border customs tourism. Form "point-line-belt" structural mode of the Yunnan Vietnam Railway promenade, developing the tourist WeChat platform that we use it to do the linkage between the tourist center and the tourists, so as to maximize the potential of tourism resources of Yunnan Vietnam railway and realize the development of Southeast Yunnan tourism.
\end{abstract}

Keywords-Yunnan Vietnam Railway; tourism development; "Point-line-band" development model; tourist WeChat platform

\section{INTRODUCTION}

Yunnan-Vietnam railway possesses all the conditions for being a historical cultural corridor, and upon now the introduction and the history of it has been documented in plenty of literatures and papers [1]. This study aims to explore a new way for protecting this heritage from the perspective of other disciplines, by a mere view on theory and the potential possibility. On the basis of field work and other scientific study, there is no doubt that it is necessary to protect and explore such a rich and complex historical and cultural heritage though the road will be a long haul.

\section{INTRODUCTION OF PROTECTION SPONSORED BY NON- GOVERNMENTAL FUNDS}

Britain is the birthplace of the world's first railway. In order to protect the heritage, London as early as in 1857 set up the South Kensington museum (the predecessor of London Science Museum) and began to collect railway cultural relics. Upon now, the museum has gathered more than 100 thousand railway culture collections, eventually becoming a living museum of British railway. For those collections, they serve as the hybrid of industrial heritage conservation and the exhibition of industrial technology. The successful experience of France on the protection of cultural heritage mainly lies in that the French government distributes the obligations and responsibilities to various agencies and eyes on integrated conservation. India with the largest number of railway industrial heritage in the world, the government collects the corresponding fund by actively applying for World Heritage Conservation Project program and making a good use of its rich abundant railway industrial heritage resources to develop tourism industry, thus to protect, exploit and utilize its relics[2].

Jiuzhaigou of Sichuan province implemented the "independent accounting, self-financing, national taxation" policy in 1983. Protection management fees are collected based on a certain proportion and are listed into the reserve service accounts. Most of those fees are specially used in conservation, tourism and exploitation. This 'fixed sum for a fixed purpose' policy has achieved good results. The ecological environment protection work of Tibet began in the 1980s and since 90s it has been further strengthened [3]. It put forward that the regional ecological environment conservation work should be closely connected with the "ecological environment protection and construction" policy proposed in Western Development Strategy and a series of guidelines and policies related to the protection of ecological environment by the central and the autonomous government, appealing for a reasonable development, not an overexploitation.

\section{PLAN FOR THE CONSERVATION OF YUNNAN- VIETNAM RAILWAY CORRIDOR AND THE TOURISM EXPLOITATION}

\section{A. Plan for the Conservation of Yunnan-Vietnam Railway Corridor}

1) Challenge of the conservation and exploitation of Yunnan-Vietnam railway: The uniqueness of the YunnanVietnam railway heritage contributes a lot to the complexity for the conservation and exploitation. The Yunnan-Vietnam railway heritage is not just a simple collection of all heritage points, but an integral representative of all the industries along the road, also a collection of all other related elements 
with the route. This is a challenge faced in the protection and exploitation of the railway, but also a great opportunity.

2) Principles for the conservation and exploitation of the Yunnan-Vietnam railiway: Yunnan-Vietnam railway, being an irreplaceable and non-renewable public resource with unique historical and cultural value both in science and art, we should reach a common sense upon the exploitation of it that it is necessary to conduct effective protection, rational utilization and sustainable development. According to the differences between the specific cultural resources and the location value and functional orientation of Yunnan Vietnam Railway Heritage Corridor, three different ways can be selectively adopted. The three ways are protection, reuse and regeneration. We integrate specific cultural resources into a whole system. Protection is more than development and suitable areas are developed first, and those that are not suitable are protected first, and then develop again when forming a virtuous cycle. It should avoid blind protection and development.

3) The scheme for protecting and developing the heritage corridor of Yunnan Vietnam Railway: In view of the particularity of the historical and cultural heritage of the Yunnan Vietnam Railway, the proposal of his protection and development is both a challenge and an opportunity. The connotation of protection and development is not the first protection and post development, but the protection development [4].The short-term -medium term- long-term protection plan is set up. First, the catalogues and historical resources catalogues of Yunnan Vietnam Railway are listed in detail. Based on the overall census data of Yunnan Vietnam Railway, the priority of historic conservation is established. Priority is given to protect the resources that are urgent and need to be protected. Second, the maintenance and management of the heritage corridor, the government should actively assist the developers in the formulation of the overall maintenance and management of the heritage corridor. Third, by constructing the overall level system of cultural heritage, we can restore and reconstruct the cultural background and cultural context, otherwise, there will be no difference from the preservation of many cultural heritage.

\section{B. Market Positioning and Development Model of the Tourism Development of Yunnan Vietnam Railway}

1) Market positioning of the tourism development of Yunnan Vietnam Railway: The fundamental factors that induce tourism behavior and motivation are the differences and contradictions between the individual's psychological state and its social environment. It is also the result of human participation in the process of socialization through tourism communication. Tourism demand is produced under the common influence and restriction of individual factors and certain social factors. In addition, tourism is also a cultural phenomenon and spiritual consumption. Therefore, the market orientation of the tourism resources development of Yunnan Vietnam Railway mainly plays the cultural brand, the international railway and the characteristic catering elements, which is different from other tourist routes. According to the investigation report of Yunnan Provincial Tourism Bureau, $29.47 \%$ of the tourist source of Yunnan is the scattered guest, which is aimed at leisure tourism. And $88.9 \%$ of urban residents travel to leisure as a purpose, while leisure for the purpose of rural tourism is 78.75\%.Therefore, the Yunnan Railway Tourism should pay attention to the cultural taste of leisure tourism.

2) Exploration on the tourism development model of Yunnan Vietnam Railway

a) The exploration of the tourism propaganda model of Yunnan Vietnam Railway: The main ways for tourists to understand Yunnan's tourism are TV, newspaper, magazine, advertising, friend introduction, network and so on[5].Television is the most influential, and newspapers and magazines are the more influential. A friend's propaganda is one of the most convincing and persuasive ways[6].And WeChat is a brand new marketing way, the speed spread, the range wide, the its impact is increasing day by day. The propaganda mode of the tourism development of Yunnan Vietnam Railway is first adopted in the traditional mode, and the WeChat propaganda should be vigorously developed. The WeChat with its unique communication characteristics can provide personalized and self-service tourism services to the mobile tourists at the fastest speed to meet the tourists' temporary needs, so as to make the innovative tourism services develop smoothly. For example, developing the app system of Yunnan Vietnam Railway, making the system a passenger line planning, scenic spot introduction, ticket purchase, consumption, accommodation and other integrated system, and answer their questions online, such as what recommendations do they have for tourist destinations. Where there is what famous snack; how the current weather and traffic, it not only saves visitors time, let tourists experience more efficient and comfortable, it also can directly understand what visitors encounter inconvenient things during the whole trip, to better targeted to provide services for tourists, true to the customer as the center. It is possible for tourists to have a mobile phone in their hands to complete the tour of the Yunnan Railway Corridor.

b) Exploration on the management of tourism operation of Yunnan Vietnam Railway: Building a tourist service inquiry center at the KunMing Railway Station. We should do well the propaganda and service of related tourism products, do the related procedures of entry and exit, and provide relevant information, such as maps, for passengers to answer questions about Yunnan Vietnam Railway special train [7].The app system of Yunnan Vietnam Railway is provided, which is a system of passenger route planning, scenic spot introduction, ticket purchase, consumption and accommodation. Tourists can solve all the problems of a long distance railway crossing on Yunnan Vietnam Railway by using a mobile phone. 
c) Marketing mode of characteristic tourist scenic area of Yunnan Vietnam Railway: Yunnan Vietnam Railway has a large spatial scale. The heritage resources are distributed in a scattered way, and the tourism resources along the route have their own characteristics. There are many world-class tourist resources, but these tourism resources are developed independently, and have not been integrated into a whole line [8].Therefore, we can take the lead of the Yunnan Provincial Tourism Development Commission to compile the master plan of the Yunnan Vietnam Railway Heritage Tourism Zone. The Yunnan Vietnam Railway Heritage tourism belt has been built as a famous tourist route both at home and abroad. We focus on creating a number of regional tourism growth points. Take Yiliang-Shilin-Mile area, Jianshui-Mengzi area and Hekou area for example; Taking the Yunnan Vietnam Railway as the development line, taking the Kunming-Mile-MengziHekou expressway as the auxiliary line, we should highlight three distinctive publicity points: the railway road leisure culture tourism, the railway road featured food and beverage tourism, the ethnic and border tourism. In order to ultimately form a form "point-line-belt" structural mode of the Yunnan Vietnam Railway promenade, so as to maximize the potential of tourism resources of Yunnan Vietnam railway and realize the development of Southeast Yunnan tourism. Construction mode of the Yunnan Vietnam Railway gallery, tourism resources are rich and have their own characteristics along the Yunnan Vietnam Railway. All localities should adhere to the principles of resource integration, differential development and dislocation competition, so as to create high-quality scenic spots with their own characteristics. Kunming, Mengzi and Hekou are three key tourist centers, taking them as a first-class tourist center, giving full play to their agglomeration and radiation effects, and then extending and radiating to other towns along the railway line.

d) Tourist products and Characteristic catering marketing: "Slow time tour" column: A fast - paced passenger sits on a small train to fully feel the beauty of nature along the way and breathe fresh air to relax the mood and relieve the pressure. This train can be designed by a Swiss mountain train.

"The tour of Yunnan and Vietnam culture": To attract the students and parents in the cold summer and summer holidays, A documentary on the train of Yunnan and Vietnam is played on the train.And they can visit some key stations and buildings on the ground, such as Yiliang, bluish village, chicken Street and human character bridge[9].

Special restaurant tour: Train the train with national characteristics. Take the local cuisine of Yunnan to the train,Such as Pu'er tea, Steamed chicken, Guoqiao rice noodle Small roll powder of Vietnam, Bean curd of Jianshui, Visitors can also taste the delicious local flavor while enjoying the beautiful scenery. Tourism is not only to enjoy the surrounding scenery, but also enjoy the tourism customs culture, so the journey which tourists expect is a collection of various elements in one trip [10].
We should build catering characteristics blocks in Mengzi, Jianshui and Hekou, the blocks should be based on the high starting point, high standard, high taste, creating a group of characteristic food blocks which have strong cultural atmosphere, distinctive national characteristics and strong national style. We will build a batch of business tourism and catering blocks with all kinds of elements in one group, and transform a number of mass blocks to satisfy consumers' multi-level and diverse needs. At the same time, in the tourist attractions and the suburbs of the city, we should develop a number of folk farm houses which has a collection of meals, accommodation, travel and shopping. A number of key tourism catering projects are planned to form a catering market system with distinctive features, reasonable layout and complete matching.

\section{CONCLUSION}

The Yunnan Vietnam Railway is one of the important materials for studying the history of Chinese railways. There are many valuable cultural relics on the Vietnam Vietnam Railway Corridor. After historical accumulation, the historical and cultural value is constantly accumulating, forming the unique cultural connotation of Yunnan. The article expounds the historical and cultural values of the Yunnan Vietnam Railway. It is suggested that the Yunnan Vietnam Railway should be reused in the protection of the railway. By referring to the experience of Railway Heritage development abroad, we built a cultural tourism development mode of Yunnan Vietnam railway, and focused on the regional culture characteristics and catering characteristics along the Yunnan Vietnam Railway. The key to build three tourism growth area, namely Yiliang-ShilinMile area, Mengzi-Jianshui area and Hekou area; Taking the Yunnan Vietnam Railway as the development line, Taking the Kunming - Mile - Mengzi - Hekou expressway as the auxiliary line, Highlighting the three characteristics of the publicity points which are Railway - Highway leisure cultural tourism, railway - Highway characteristic catering tourism, national and border customs tourism. Form "pointline-belt" structural mode of the Yunnan Vietnam Railway promenade, so as to maximize the potential of tourism resources of Yunnan Vietnam railway and realize the development of Southeast Yunnan tourism.

\section{REFERENCES}

[1] Wang Zhifang et al. Heritage corridor - a new method for the protection of American historical and cultural heritage, [J]. Chinese garden, 2001 (5):85-88.

[2] Yu Kongjian; Zhu Qiang; Li Dihua. The construction of the the Grande Canale industrial heritage corridor in China: ideas and principles [J]. construction technology, 2007, (13): 167-173.

[3] Duan xi.Yunnan Vietnam Railway - a small train across the century [Z]. Kunming: Yunnan Art Press, 2007.

[4] Lin Che.A number of econometric models in the economic history of modern Yunnan $[\mathrm{J}]$. Journal of Yunnan University of Finance and Economics, 2007, (2): 123-173.

[5] Wang Jinghui.the protection of historical and cultural heritage[J] Planner, 2002 (6):9-13.

[6] Li Wei. The new trend of the world cultural heritage protection -- city cultural routes[J].Urban problems, 2005 (4). 
[7] Li Wei. Introduction of an international literature on the protection of large scale cultural heritage, [J]. Chinese cultural relics, 2005. (3).

[8] Zhang song. An introduction to the history of urban conservation science -- an integrated method of cultural heritage and historical environmental protection $[\mathrm{C}]$. Shanghai: Shanghai science and Technology Press, 2001:140.

[9] Li Wei, Yu Kongjian, Li Dihua. The theoretical framework of heritage corridor and Beijing Hangzhou the Grande Canale overall protection [J]. city problem, 2004, (1):12-16.

[10] Li Fang Li Qinglei Li Liangliang on the tourism development of the transportation Heritage: Taking the Yunnan Vietnam Railway as an example, [J], the 22 volume of urban development research in the 10 period of 2015: 57-62. 